\title{
Hypoglycemia with lactic acidosis caused by a new MRPS2 gene mutation in a Chinese girl: a case report
}

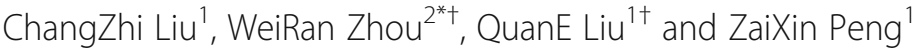

\begin{abstract}
Background: Mitochondrial ribosomal protein S2 (MRPS2) gene mutation, which is related to severe hypoglycemia and lactic acidosis, is rarely reported globally.

Case presentation: We report a case of a new MRPS2 gene mutation in a Chinese girl who presented with hypoglycemia and lactic acidosis. A homozygous C.412C > G variant that could cause complex oxidative phosphorylation deficiency and had not been reported before was identified. The clinical manifestations included recurrent vomiting, hypoglycemia, lactic acidosis, sensorineural hearing loss, and gall bladder calculi. Hypoglycemia and lactic acidosis improved after the administration of sugary liquid and supportive treatments.
\end{abstract}

Conclusions: Recurrent hypoglycemia with lactic acidosis and sensorineural hearing loss should lead to suspicion of mitochondrial defects and the early refinement of genetic tests.

Keywords: MRPS2, Hypoglycemia, Lactic acidosis, Case report

\section{Background}

Hypoglycemia with lactic acidosis is rarely seen in clinical practice. Despite early treatment, hypoglycemia with lactic acidosis still has a high mortality rate. The main causes of hypoglycemia and lactic acidosis include the blood system of malignant tumor, septicemia, renal insufficiency, malaria, certain drugs, and mitochondrial dysfunction [1].

Mitochondrial diseases are important causes of hypoglycemia and lactic acidosis. Defects in mitochondrial translation in mitochondrial diseases could lead to complex oxidative phosphorylation system (OXPHOS) deficiency, which may cause severe multisystem dysfunction early in life and even death [2-4].

\footnotetext{
* Correspondence: Weiranxue2014@163.com

'WeiRan Zhou and QuanE Liu contributed equally to this work.

${ }^{2}$ Jinan Children's Hospital (Qilu Children's Hospital of Shandong University), Jinan, China

Full list of author information is available at the end of the article
}

Most of the mitochondrially encoded proteins are core subunits of OXPHOS comprising the respiratory chain and ATP synthase [5]. The biogenesis of mitochondrial OXPHOS depends on mitochondrial-specific ribosomes in the mitochondrial matrix for the translation of 13 mtDNA-encoded polypeptides [4]. The mitochondrial genetic system takes charge of the post-translation maturation of the newly synthesized polypeptides. However, how these activities are organized and coordinated is largely unknown [5].

Mutations in nine mitochondrial ribosomal proteinencoding genes, including mitochondrial ribosomal protein S2 (MRPS2), have been reported. MRPS2 mutations have been found in two patients [4]. In the present study, we report a case of recurrent hypoglycemia with lactic acidosis in a school-aged child caused by a new MRPS2 mutation, which has not been reported, to reveal a rare cause of hypoglycemia and lactic acidosis in MRPS2 mutation and learn the phenotype of the MRPS2 gene.

(C) The Author(s). 2021 Open Access This article is licensed under a Creative Commons Attribution 4.0 International License, which permits use, sharing, adaptation, distribution and reproduction in any medium or format, as long as you give appropriate credit to the original author(s) and the source, provide a link to the Creative Commons licence, and indicate if changes were made. The images or other third party material in this article are included in the article's Creative Commons licence, unless indicated otherwise in a credit line to the material. If material is not included in the article's Creative Commons licence and your intended use is not permitted by statutory regulation or exceeds the permitted use, you will need to obtain permission directly from the copyright holder. To view a copy of this licence, visit http://creativecommons.org/licenses/by/4.0/ The Creative Commons Public Domain Dedication waiver (http://creativecommons.org/publicdomain/zero/1.0/) applies to the data made available in this article, unless otherwise stated in a credit line to the data. 


\section{Case presentation}

The girl aged 6.5 years old was hospitalized because of recurrent vomiting for more than 2 years. She had poor appetite and hypoglycemia during hospitalization but without seizures and unconsciousness. Her condition improved after the administration of sugary liquid and supportive treatments. However, her hypoglycemia was recurring. The girl was taciturn with language retardation. She could only say simple words and sentences, but her motor development was normal. When she was 4 years old, she had sensorineural hearing loss and was treated by parallel cochlear implants. When she was 4 years and 9 months old, she had gall bladder calculi due to chronic cholecystitis, which was accompanied by erosion and bile reflux, and was treated by laparoscopic cholecystectomy under general anesthesia. She was G2P2 and born naturally at term. Her brother was healthy, and the siblings had no similar medical history or family history.
Physical examinations revealed no abnormal findings. Muscle tension and tone were normal. The results of blood tandem mass spectrometry and urine gas chromatography were normal. Blood glucose was $1.2-2.5 \mathrm{mmol} / \mathrm{L}$ when she was hospitalized. She had metabolic acidosis (pH: 7.224 [reference value: 7.35-7.45], HCO3-: $4.3 \mathrm{mmol} / \mathrm{L}$ [reference value: $22-26 \mathrm{mmo} / \mathrm{L}$ ), base excess: $-24 \mathrm{mmol} / \mathrm{L}$ (reference value: $3 \mathrm{mmol} / \mathrm{L}$ ), lactate: $8.9 \mathrm{mmol} / \mathrm{L}$ [reference value: $0.5-1.5 \mathrm{mmol} / \mathrm{L}]$ ) and normal liver enzyme, blood lipid, myocardial enzyme level, and thyroid function.

The cause of the recurrent hypoglycemia was unknown; therefore, a gene test was performed, and a new homozygous MRPS2 gene mutation, C.412C $>\mathrm{G}$ (p.R138G), was found (chromosome location: chr9: 138395500), as shown in Fig. 1.

\section{Treatment and prognosis}

The child was repeatedly hospitalized because of vomiting and hypoglycemia. She was treated by glycemia. Her

\section{Verification site: MRPS2,c.412C>G, chromosome location: chr9: 138395500}

\section{Evidence: homozygous mutation at chr9: 138395500 location}

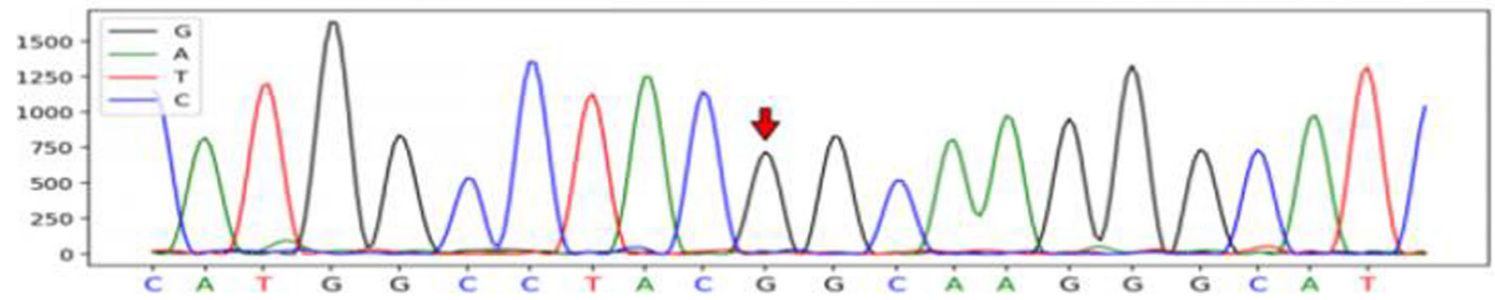

Father: heterozygous mutation in chr9: 138395500 position

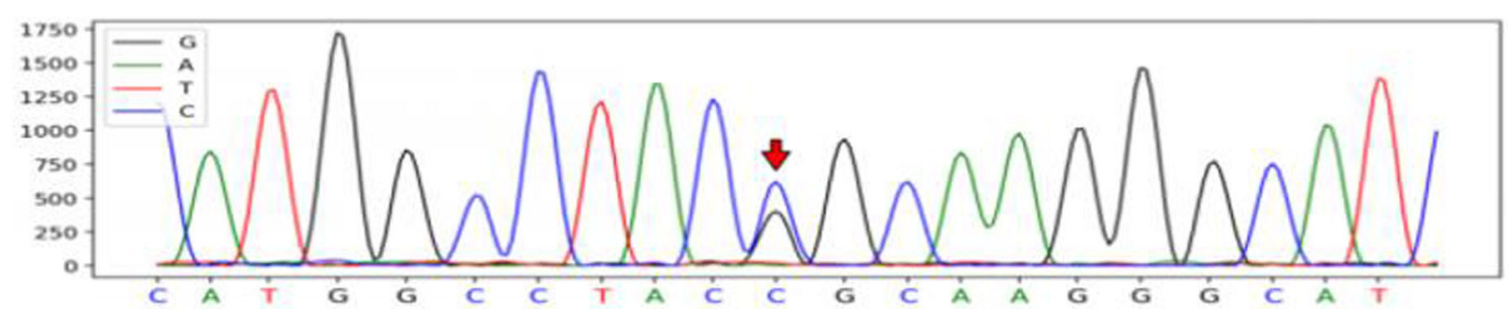

Mother: heterozygous mutation in chr9: 138395500 position

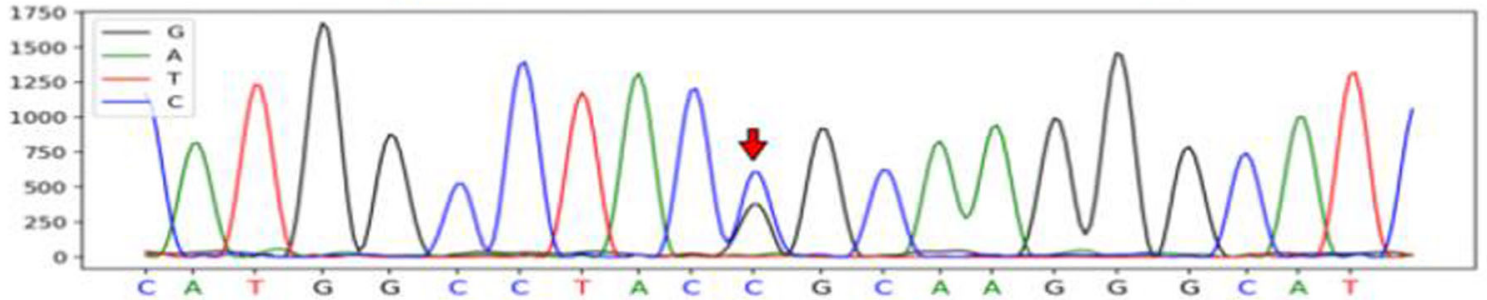

Fig. 1 Genomic sequences of the MRSP2 gene. The proband had the homozygous mutation C. $412 \mathrm{C}>\mathrm{G}(\mathrm{p} . \mathrm{R} 138 \mathrm{G})$. The parents of the proband were all heterozygous for this mutation 
appetite recovered as her blood glucose became normal. Her hearing loss was corrected and her speech development improved after cochlear implantation and speech rehabilitation, respectively. The current course of the disease was more than 2 years. The girl was 7 years old with a weight of $15.6 \mathrm{~kg}$ and a height of $111 \mathrm{~cm}$. Her language developed normally. She was rated as moderate by Baby-Junior Middle School Students Social Living Ability Scale, and she could attend kindergarten like normal children.

\section{Discussion and conclusions}

This case is the first Chinese case of MRPS2 gene mutation, which has the potential to lead to OXPHOS deficiency. Gardeitchik et al. [4] reported two children with MRSP2 mutation for the first time in 2018 with clinical manifestations of sensorineural deafness, hypoglycemia, lactic acidosis, 2-oxoglutarate acidurea, and developmental retardation. Both children survived and were 11 years old during the follow-up. They used fibroblasts obtained from skin biopsies of both subjects to characterize the effects of the identified variants and found that MRPS2 mutation makes the protein unstable and thus damages the assembly of the small subunit mitochondrial DNA (MT-SSU), a part of a dedicated translation machinery that could execute mitochondrial translation. In other words, the reduction of MT-SSU assembly caused by MRPS2 mutations could lead to the inhibition of mitochondrial translation and a variety of OXPHOS defects.

MRPS2 was also studied in tumors. MRPS2 upregulated in patients with follicular thyroid tumors caused by dysfunctional mitochondrial metabolism [6]. The ribosomal fraction in patients with mutations of mitochondrial small subunit ribosomal proteins, MRPS16 and MRPS22, is still about $60 \%$ of the control levels of MRPS2. This result suggests that the stability of MRPS2 is not strongly affected. Indeed, MRPS2 may play a major structural role [7].

In this case, a new mutation, C. $412 \mathrm{C}>\mathrm{G}$, was found in MRPS2. The homozygous mutation is consistent with the autosomal recessive genetic pattern of the disease, and the gene-associated disease is consistent with the clinical manifestation of the proband. Notations according to the American College of Medical Genetics and Genomics Standards and Guidelines are as follows: PM1: the variation is located in a functional domain; PM2: the variation is absent from controls in the Exome Sequencing Project, 1000 Genomes Project, or Genome Aggregation Database; PP3: Sift, PolyPhen-2, and MutationTaster show multiple lines of computational evidence to support a deleterious effect on the gene or gene product. Therefore, the variation was considered pathogenic. Regretfully, we did not perform further experiments to prove the functions of the variant.
We paid attention to other MRPS mutations. Ninetyeight mitochondrial protein-coding genes have been reported to date. Among the patients, two siblings had MRPS7 mutation (MIM: 611974) [8]; one had MRPS16 mutation (MIM: 609204) [9]; five had MRPS22 mutation (MIM: 605810), including 3 siblings [10]; and the rest had mutations in MRPS34 (MIM: 611985) [11], MRPL3 (MIM: 607118) [12], MRPL12 (MIM: 602375) [13], MRPL44 (MIM: 611849, [14], and MRPS2 [4]. A total of 24 subjects have been reported, all of whom had disease onset as newborn or infants. Defects in MRPS22 and MRPS34 led to early fatal phenotypes. One case with MRPS16 defect died 3 days after birth; four of the five cases with MRPS22 defects died early, and two of the cases with MRPS34 defects died in infancy because of respiratory failure. In addition, two of the four siblings with defects in MRPL3 died at 15 and 17 months, whereas the other two siblings were still alive at 3 years of age. Among the cases with MRPS7 defects, one case died at 14 years old, and the others were followed up to 1.5-26 years old. The rest were survival cases, and the oldest one had a MRPL44 defect.

Clinically, two patients with MRPS23 [15] defect reported hypoglycemia. In addition to MRPS23, all patients had lactic acidosis. The remaining clinical manifestations included cardiac involvement, such as cardiomyopathy, retinitis, redundancy of the skin of the neck, cranial deformity, and hearing impairment.

This case is the first reported MRPS2 mutation among Chinese. The girl suffered from recurrent hypoglycemia, lactic acidosis, and sensory neurologic deafness with normal intellectual and motor development. The mechanism of the new MRSP2 mutation needs to be further studied, and the prognosis still needs to be confirmed by long-term follow-up. When we encounter school-aged children with hypoglycemia accompanied by lactic acidosis, we should pay attention to mitochondrial diseases after excluding infection, malignant tumor, drugs, and other factors. Mitochondrial gene detection can help detect related mutations and make an accurate diagnosis.

\section{Abbreviations \\ MRPS2: Mitochondrial ribosomal protein S2; OXPHOS: oxidative phosphorylation system \\ Acknowledgements \\ We are grateful to the patient and her family who kindly consented to join the study. \\ Authors' contributions \\ LCZ collected data, drafted the initial manuscript, and reviewed and revised the manuscript. ZWR conceptualized and designed the study, critically reviewed and revised the manuscript. LQE and PZX coordinated and supervised data collection, and reviewed the manuscript. All authors have read and approved the manuscript.}

Funding

This study received no funding. 


\section{Availability of data and materials}

The data that support the findings of this study are available from the. corresponding author upon reasonable request.

\section{Declarations}

\section{Ethics approval and consent to participate}

All procedures in this study were approved by the Ethics Committees of Xiangxi Autonomous Prefecture People's Hospital. As the participant under the age of 16 , written informed consent to participate was obtained from her parents.

\section{Consent for publication}

As the patient was under the age of 16 , written informed consent for publication of clinical details and/or clinical images was obtained from her parents.

\section{Competing interests}

The authors declare that they have no competing interests.

\section{Author details}

${ }^{1}$ Xiangxi Tujia and Miao Autonomous Prefecture People's Hospital, Jishou, China. ${ }^{2} J i n a n$ Children's Hospital (Qilu Children's Hospital of Shandong University), Jinan, China.

Received: 3 January 2021 Accepted: 21 December 2021

Published online: 06 January 2022

\section{References}

1. Talwalkar PG. Severe and persistent hypoglycemia with lactic acidosis in an elderly lady with type 2 diabetes mellitus and lymphoma\leukemia: a rare case report. Diabetes Metab Syndr. 2019;13(1):648-50. https://doi.org/10.101 6/j.dsx.2018.11.037

2. Pearce $S$, Nezich $C L$, Spinazzola A. Mitochondrial diseases: translation matters. Mol Cell Neurosci. 2013;55:1-12. https://doi.org/10.1016/j.mcn.2012. 08.013.

3. Greber BJ, Boehringer D, Leibundgut M, Bieri P, Leitner A, Schmitz N, et al. The complete structure of the large subunit of the mammalian mitochondrial ribosome. Nature. 2014;515(7526):283-6. https://doi.org/10.1 038/nature13895.

4. Gardeitchik T, Mohamed M, Ruzzenente B, Karall D, Guerrero-Castillo S, Dalloyaux $\mathrm{D}$, et al. Bi-allelic mutations in the mitochondrial ribosomal protein MRPS2 cause sensorineural hearing loss, hypoglycemia, and multiple OXPHOS complex deficiencies. Am J Hum Genet. 2018;102(4):68595. https://doi.org/10.1016/j.ajhg.2018.02.012.

5. Singh AP, Salvatori R, Aftab W, Aufschnaiter A, Carlstrom A, Forne I, et al. Molecular connectivity of mitochondrial gene expression and OXPHOS biogenesis. Mol Cell. 2020;79(6):1051-65. https://doi.org/10.1016/j.molcel.202 0.07.024.

6. Jacques C, Guillotin D, Fontaine JF, Franc B, Mirebeau-Prunier D, Fleury A, et al. DNA microarray and miRNA analyses reinforce the classification of follicular thyroid tumors. J Clin Endocrinol Metab. 2013;98(5):E981-9. https:// doi.org/10.1210/jc.2012-4006

7. Emdadul HM, Grasso D, Miller C, Spremulli LL, Saada A. The effect of mutated mitochondrial ribosomal proteins S16 and S22 on the assembly of the small and large ribosomal subunits in human mitochondria. Mitochondrion. 2008;8(3):254-61. https://doi.org/10.1016/j.mito.2008.04.004.

8. Menezes MJ, Guo Y, Zhang J, Riley LG, Cooper ST, Thorburn DR, et al. Mutation in mitochondrial ribosomal protein S7 (MRPS7) causes congenital sensorineural deafness, progressive hepatic and renal failure and lactic acidemia. Hum Mol Genet. 2015;24(8):2297-307. https://doi.org/10.1093/ hmg/ddu747.

9. Miller C, Saada A, Shaul N, Shabtai N, Ben-Shalom E, Shaag A, et al. Defective mitochondrial translation caused by a ribosomal protein (MRPS16) mutation. Ann Neurol. 2004;56(5):734-8. https://doi.org/10.1002/ana.20282.

10. Saada A, Shaag A, Arnon S, Dolfin T, Miller C, Fuchs-Telem D, et al. Antenatal mitochondrial disease caused by mitochondrial ribosomal protein (MRPS22) mutation. J Med Genet. 2007;44(12):784-6. https://doi.org/10.113 6/jmg.2007.053116.

11. Lake NJ, Webb BD, Stroud DA, Richman TR, Ruzzenente B, Compton AG, et al. Biallelic mutations in MRPS34 lead to instability of the small mitoribosomal subunit and leigh syndrome. Am J Hum Genet. 2017;101(2): 239-54. https://doi.org/10.1016/j.ajhg.2017.07.005.

12. Galmiche L, Serre V, Beinat M, Assouline Z, Lebre AS, Chretien D, et al. Exome sequencing identifies MRPL3 mutation in mitochondrial cardiomyopathy. Hum Mutat. 2011;32(11):1225-31. https://doi.org/10.1002/ humu.21562.

13. Serre V, Rozanska A, Beinat M, Chretien D, Boddaert N, Munnich A, et al. Mutations in mitochondrial ribosomal protein MRPL12 leads to growth retardation, neurological deterioration and mitochondrial translation deficiency. Biochim Biophys Acta. 2013;1832(8):1304-12. https://doi.org/10.1 016/j.bbadis.2013.04.014.

14. Distelmaier F, Haack TB, Catarino CB, Gallenmuller C, Rodenburg RJ, Strom TM, et al. MRPL44 mutations cause a slowly progressive multisystem disease with childhood-onset hypertrophic cardiomyopathy. Neurogenetics. 2015; 16(4):319-23. https://doi.org/10.1007/s10048-015-0444-2.

15. Kohda M, Tokuzawa Y, Kishita Y, Nyuzuki H, Moriyama Y, Mizuno Y, et al. A comprehensive genomic analysis reveals the genetic landscape of mitochondrial respiratory chain complex deficiencies. Plos Genet. 2016;12(1): e1005679. https://doi.org/10.1371/journal.pgen.1005679.

\section{Publisher's Note}

Springer Nature remains neutral with regard to jurisdictional claims in published maps and institutional affiliations.
Ready to submit your research? Choose BMC and benefit from:

- fast, convenient online submission

- thorough peer review by experienced researchers in your field

- rapid publication on acceptance

- support for research data, including large and complex data types

- gold Open Access which fosters wider collaboration and increased citations

- maximum visibility for your research: over $100 \mathrm{M}$ website views per year

At BMC, research is always in progress.

Learn more biomedcentral.com/submissions 